PLEASE NOTE! THIS IS SELF-ARCHIVED VERSION OF THE ORIGINAL ARTICLE

To cite this Article: H. Seppälä, F. Adaikalam, P. Marjanen (2017) INNOVATIVE PERSONAL LEARNING ENVIRONMENT AS A MEDIATOR FOR CROSS-BORDER EDUCATION EXPORTS AND SKILL DEVELOPMENT, ICERI2017 Proceedings, pp. 8133-8138.

doi: $10.21125 /$ iceri.2017.2181

URL: https://library.iated.org/view/SEPPALA2017INN 


\title{
INNOVATIVE PERSONAL LEARNING ENVIRONMENT AS A MEDIATOR FOR CROSS-BORDER EDUCATION EXPORTS AND SKILL DEVELOPMENT
}

\author{
Heikki Seppälä ${ }^{1}$, Francis Adaikalam², Päivi Marjanen ${ }^{3}$ \\ ${ }^{1}$ Laurea University of Applied Sciences (FINLAND) \\ ${ }^{2}$ Loyola College (INDIA) \\ ${ }^{3}$ Laurea University of Applied Sciences (FINLAND)
}

\begin{abstract}
This article reports how Personal Learning Environments (PLE) can act as a facilitator for education exports between Finland and India. This paper results from the Eurostars project "TRIBA", the world's first online social learning platform utilizing Smart Learning Data. First, this article introduces how the educational landscape is moving towards self-directed learning and how technology is shaped by structural demands of society. Then, it describes key factors that drive the development of the Elearning market in India. Next, it discusses the challenges and drawbacks of using MOOCS (Massive Open Online Course), and how PLE attempt to solve these by structuring the learning environment. After that, it describes the methodological approach. Then it introduces the main findings related to requirements, usage, possibilities, and challenges of PLE providers entering the Indian market. Finally it draws the conclusions.
\end{abstract}

Keywords: Personal learning environment, Adaptive eLearning, Personalization and Profiling, Education export, MOOCs, Market entry, Social construction of technology, Co-creation

\section{INTRODUCTION}

Formal education is typically based on traditional classroom teaching, fixed deadlines, assessment tasks and criteria defined by teachers. The trend is moving away from traditional education towards self-directed learning and the inclusion of technologies in ways that meet their needs and preferences [1]. It is noted that many of the students graduating from formal education lack the skills required by the working life. Recent studies showed that on an average, only $42 \%$ of employers felt that new hires were ready for work. In India almost $83 \%$ of educational institutions believe that their graduates are ready for the market, but only $51 \%$ of employers agree with that [2]. Hence, alternative ways for educating people with relevant skills is required to match the employer's need. Currently there are plenty of online learning possibilities where to choose from with MOOCs being the most popular. The "education for masses" works for some time but the approach does not come without pitfalls.

In this paper we present a case where we examine the possibilities for Personal Learning Environments (PLE) to act as a facilitator for education exports between Finland and India, with emphasis in sectors that are identified as country specific expertise areas with high growth potential. The focus is on educational collaboration between India and Finland and how the use of educational technology could help in establishing mutually beneficial relationships. It is useful to discuss how educational technology can be adapted for a multicultural society like India through Sociological understanding of technology. This study is carried out under the Eurostars/Tekes funding scheme, in a project called TRIBA and in collaboration with a Personal Learning Environment (PLE) company called Claned. A Personal learning environment helps learners to take control and manage their own learning. PLEs support learners to set learning goals, manage and process learning content, and communicate with other learners. CLANED algorithms gather intelligent information on users' interaction with education materials, peers and teachers. This offers valuable knowledge of how learning happens and what impacts its success - and how it can be further developed. The Smart Learning Data that is gathered is returned to students, teachers and education and content providers, bringing valuable information and benefits to all parties [3]. TRIBA-project aims to facilitate fruitful collaboration between organisations, content providers and educators that recognises the individual needs of learners and at the same time recognize the requirements from working life. 
Social Construction of Technology argues that technology has been shaped by the structural demands of the society. Pinch and Bijker argued for 4 components in shaping the technology. Firstly, interpretative flexibility, secondly based on social group with a premise that the social group is a homogenous entity. Thirdly, based on the closure and stabilisation (how the multi-group design the whole process and finalise it) and lastly, the sociocultural, political and economic context [4]. But many others have recorded on how the asymmetric social reality impact the way technology is shaped and used. For example, Russell [4] acknowledges that the technological artefact is not shaped by a single or bunch of group but rather it is based on the negotiation or involvement of diverse groups. Haard [5] details out on the inter and intra-group conflict which would have led to choose one type of artefact compared to other. Kline and Pinch [6] examines the role of gender in designing automobiles. For the Indian Case access to educational technology largely depends on the social position one is placed, physical location of the individual, availability and access to educational tools and technological artifacts. These socio, political, economic and cultural asymmetry decides the use of technology and very specifically educational technology in India.

\section{E-LEARNING IN INDIAN CONTEXT}

India's online education market is set to grow to USD 1.96 billion and around 9.6 million users by 2021 from USD 247 million and around 1.6 million users in 2016. An RNCOS report titled, 'Booming Distance Education Market Outlook 2018' expects the distance education market in India to grow at a compound annual growth rate (CAGR) of around 34 per cent during 2013-14 to 2017-18. Moreover, the aim of the government to raise its current gross enrolment ratio to 30 per cent by 2020 will also boost the growth of the distance education in India [7].

The key factors leading to the growth of the E-learning market in India include low education coverage, rising demand from various segments, growing personal computers and Internet penetration, increasing government participation and convenience factors. Strong opportunity exists in the market due to low coverage of education in India and skill mismatch between learner and employer [8]. Hence, Technological advancements in countries like India has posed both opportunities and challenges. Learning and its outcome is not asymmetry but rather a lopsided effect since individuals exposed to multiple realities have both utilised optimally and never heard of such online platform. Cultural inhibition and structurally graded hierarchical communities will have a long lasting impact on the usability of such platforms. Social, cultural and linguistic differences within India placed education to be in concurrent list. It means both the Union (Centre) Government and the 25 Provincial (State) Governments will work in tandem. Adding to this is the issues of access and availability of educational needs to already asymmetric communities. Hence it's a herculean task for the educational technology to realise its fullest potential given the nature of India's diverse and lopsided education system. Apart from this the challenge PLE would also be to meet the requirements of at least 22 recognised languages and possibly hundreds of local dialects and to reach 1.25 billion population [9] [10]. New patterns of inequality of outcomes based on class, gender and geographic location are formed as some groups are more able to draw on cultural and economic resources than others to secure success.

These factors and demands from other education segments rise and will drive the e-learning market. Apart from schools adapting to multiple audio-visual learning methods, online learning platforms are popular among young learners in India especially among urban youth. Even though some of these online learning courses are in tune with existing curriculum, they are not taken into consideration while awarding degrees. Yet, the Federal Government under its autonomous bodies promotes online courses to match the increasing enrolment rates in higher education. One of the key rationale is cost cutting in higher education and to encourage technology induced learning. In India technological institutions have created online courses to suit AICTE syllabus for a pan Indian students. Since the quality of teaching among the rural and even in urban areas are cause of concern. Online learning has huge potential in India to address access and equity, considering only $24.5 \%$ among $18-23$ years of age group enrolled for higher education and with a sixty percent of colleges are located in rural areas [11]. In India, there are other learning platforms mainly for science and engineering courses. One such joint initiative is National Programme on Technology Enhanced Learning (NPTEL) by seven public funded Indian Institute of Technologies and Indian Institute of Science. The lectures follow the prescribed curriculum approved by All India Council for Technical Education (AICTE) [12]. 


\section{CHALLENGES OF MOOCS}

In 2011, Stanford computer scientists Sebastian Thrun and Peter Norvig came up with the idea of streaming their course over the Internet. Through the Internet, learners could log on to lectures streamed to wherever they happened to be. When more than 160,000 students enrolled in Thrun and Norvig's introduction to artificial intelligence MOOC, the professors thought they had accomplished a way to educate masses in a new and efficient way [13]. The reality kicked in later when a survey of 34,779 students worldwide was carried out by University of Pennsylvania showing that the average MOOC course completion rate was less than 7 percent [14]. Moreover, it came evident that some people quit watching the material within the first few minutes and many others were merely browsing, taking advantage of the technology to quickly log in, absorb just the info they were hunting for, and then log off. Another review of MOOCs [15] found out that nearly $90 \%$ of students starting a course drop out due to lack of motivation or engagement, having insufficient prior knowledge about the topic or experiencing the assignments and materials as ambiguous.

Even if the completion rates would be rising in MOOCs, they do not tell much about the learning outcomes. There is a rising need for MOOCs to support the notion that instructional quality, feedback mechanisms and learning analytics play a significant role in them. Low completion rates, lack of pedagogical infrastructure, and unreliable assessment methods have led to increasing criticism of MOOCs in research where the focus has shifted on students' learning outcomes [16]. Thus, knowing more about what and how students learn would provide data for designing ways to address the challenges faced in MOOCs.

A recent article [17] that studied the learning outcomes in MOOCs came up with four implications of MOOC quality. 1) Timely feedback is considered to be important as it is positively related to students' meaningful learning. 2) Assessing student performance with methods that are aligned with learners' needs and motivations. This requires also adaptation from the platform's assessing features. 3) The differences in learning outcomes of experienced and novice MOOCers, and how these differences are related to the learning behaviors they exhibit during a MOOC. 4) Analytics that can unveil the relationships between students' characteristics, course features, learning and teaching activities, and students' learning outcomes in MOOCs.

Even though there is a rhetoric that MOOCs will offer opportunity to learners from developing countries' who currently don't have direct access to learning opportunities, especially at higher levels, there is a growing concern that MOOCs might be serving only the 'privileged' in developing countries who are already part of the digital boom and have 'access' to international language learning [18]. The individuals the MOOC revolution is supposed to help the most-those without access to education in developing countries-are under represented among the early adopters in some countries where MOOCs are popular, such as Brazil, China, India, Russia, and South Africa. Nearly, 80 percent of MOOC students come from the wealthiest and most well educated 6 percent of the population [15].

A recent paper in Science magazine [19] also explored a lesser-known barrier to online learning. It suggested that students of MOOCs in less developed countries "may suffer from the cognitive burden of wrestling with feeling unwelcome while trying to learn and [may] therefore underperform". "This can be exacerbated by social identity threat, which is the fear of being seen as less capable because of one's group."

\section{PERSONAL LEARNING ENVIRONMENTS (PLE)}

Personal Learning Environments (PLE) attempts to solve the problems described above by structuring the learning environment. The PLE case company, Claned has developed a system that adapts according to the users' priorities, learning goals and skill level. Their goal is to construct a place where people feel supported and comfortable to engage with fellow learners in an open online environment. In other words, the user could sign in and get support to reach her learning goal and be scaffolded in search for competence in the skill or knowledge of her choice [3]. The platform uses a combination of artificial intelligence and educational psychology theories. Based on this combination, it begins to understand how each student learns and what the factors affecting his or her learning processes and study performance are. On the basis of the insights that the algorithm provides, students are recommended study buddies, learning materials, and mentors that best suit their needs. Claned is a 
move towards a space for aggregating content in a learner community where dialogue takes place, and interactions and content can be accessed and engaged with ease [20].

\section{METHODOLOGICAL APPROACH}

As indicated previously, in this paper we examine the possibilities for PLE to act as a facilitator for education exports between Finland and India. The methodologies that are used include a desk research, three Skype interviews, and five onsite interviews and co-creation workshops during a field trip in India. The data was categorized using content analysis by making a data-based analysis of the research data [21].

This applied research focuses on the case company Claned and aims to assess what kind of elearning technologies are currently used in India while gathering feedback on the (potential) usage of personalized learning environments. Further, possibilities and challenges for PLE providers entering the Indian market are identified. Persons from both the educational sector and business life were selected for the interviews and workshops.

\section{RESULTS}

While innovation in education in India is progressing substantially, the gross amount of educational providers still have a very traditional approach to education. One of the main reasons for this, as indicated by all eight interviewees, is that intensive competition through grading and ranking still dominates how students are accepted at recognized educational institutions and in companies. Intensive testing and comparing kids and students with each other occurs already from Early Childhood Education and onwards. For the time being it seems that new innovative approaches will need to be gradually introduced in order to be accepted by the wider public.

PLE providers have the possibilities to provide an educational solution that can cater both traditional and innovative educational approaches, as well as facilitate gradual changes and adaptations in the industry. Both traditional educational elements (such as testing, and giving presentations), as well as more innovative ways for learning can be combined depending on the individual needs of the learners and teachers. PLE provides Indian educational organizations with a scalable solution, while focusing on individual learning, through personalized learning paths.

Technological advancements in countries like India has posed both opportunities and challenges. Some are fully exposed from younger days whereas others have limited or no exposure to such online tools. Moreover online platforms have either not developed fully or they are non-existent in many languages. Hence, these structural barriers and social realities will have a long lasting impact on the usability of such platforms.

Entering the Indian market can be highly rewarding, but doesn't come without challenges. Firstly, from a pricing perspective, the Indian market is very cost conscious, especially when it comes to technological solutions. India is considered as one of the main IT hubs in the world, and has an enormous supply of digital solutions. "Any PLE offered in this market needs to provide clear added value compared with local available solutions as well as available MOOCs" was stated by an interviewee from the digital development team of a local school in Chennai.

Consumer behavior is affected by the cost of learning, flexibility offered while learning and also on the level of the qualification of customers. As e-learning serves a horizontal market, focus on a targeted set of consumers when it comes to content generation or collation is very important. Regulatory norms and curriculum (when catering to educational institutes), corporate and consumer requirements have to be met through e-learning content [22]. Key requirements that were mentioned by the interviewees included job promise, certification, and local presence. Job promise is a driving factor that would encourage learners to purchase educational courses and degrees. Local or international enterprises that could potentially provide guaranteed jobs upon completion of degrees and modules would increase the attraction factor substantially. Certification was mentioned to be another motivator, since it would allow students to clearly differentiate themselves from competition when applying for a job. Thirdly local support and visibility for sales as well as service delivery were considered important. 


\section{CONCLUSIONS}

This article explained the positioning of Personal Learning Environments in Indian context. First, it described the landscape and developments of the e-learning market. Next, it discussed the challenges and drawbacks of using MOOCS, and how PLE attempt to solve these. Finally it identified the main challenges and opportunities for Finnish PLE providers entering the Indian market. PLE has the potential to become an educational solution that can cater both traditional and innovative educational approaches, as well as facilitate gradual changes and adaptations in the industry in India. It is a scalable solution that enables individual learners to follow their personalized learning paths. Effective personalized learning environments provide tools and learning resources that students use in selfdirected and self-paced manner. Because learning is deepest with guidance and interaction, the content and tools should be collaborative. Any PLE provider aiming to enter the Indian market needs to be well aware about local conditions, e.g. available solutions by competitors, stakeholder requirements associated with educational provision such as job promise, certification, and local support, as well as regulatory norms and curriculum requirements.

\section{ACKNOWLEDGEMENTS}

This study has been financed by Tekes and the Eurostars EU project EU9666.

\section{REFERENCES}

References [Arial, 10-point, left alignment, upper and lower case] should be cited according to the Bibliography and Citation Style https://iated.org/citation_guide

[1] M. Prensky. "Engage me or enrage me": What today's learners demand. Educause Review, 40(5), pp. 60-65, 2005. Retrieved from http://www.educause.edu/ir/library/pdf/ERM0553.pdf

[2] S. Raina (July 2017). Bridging the Skills Gap. The Smart Manager, pp. 75-79, 2017. Retrieved from http://www.talerang.com/pdfs/Talerang-Smart-Manager-Article.pdf

[3] T. Litmanen \& I. Autio, "Intelligent Tutoring in Online Learning Environment," in 10th International Technology, Education and Development Conference Valencia, Spain. 7-9 March, 2016. Retrieved from https://claned.com/assets/eurostars/Litmanen-AutioIntelligentTutoring.pdf

[4] T. Pinch \& W. Bijker, "The social construction of facts and artifacts: Or how the sociology of science and the sociology of technology might benefit each other," In The social construction of technological systems: New directions in the sociology and history of technology, W. Bijker, T. Hughes, \& T. Pinch, Cambridge, MA: MIT Press, pp. 17-50, 1987.

[5] M. Haard, "Beyond harmony and consensus: A social conflict approach to technology," Science, Technology, and Human Values, vol. 18(4), pp. 408-432, 1993.

[6] R. Kline \& P. Trevor, "Users as agents of technological change: The social construction of the automobile in the rural United States," Technology and Culture, vol.37 (4), 763-795, 1996.

[7] Online Education in India: 2021. A Study by KPMG in India and Google. May 2017. Retrieved from https://assets.kpmg.com/content/dam/kpmg/in/pdf/2017/05/Online-Education-in-India2021.pdf

[8] LMS in India Market Research 2012. Endurance Group Inc. Retrieved from http://endurancegrp.com/Lms_Market.pdf

[9] Constitutional provisions relating to Eighth Schedule. (September 2017). Retrieved from http://mha.nic.in/hindi/sites/upload_files/mhahindi/files/pdf/Eighth_Schedule.pdf

[10] J. Wyn, Touching the Future: Building skills for life and work, Australian Council for Educational Research, 2009. Retrieved from http://research.acer.edu.au/cgi/viewcontent.cgi?article=1008\&context=aer\&seiredir=1\&referer=http\%3A\%2F\%2Fscholar.google.fi\%2Fscholar\%3Fq\%3Dfuture\%2Bskills\%2Bo ecd\%26hl\%3Dfi\%26as_sdt\%3D0\%26as_vis\%3D1\%26oi\%3Dscholart\%26sa\%3DX\%26ved\%3D OahUKEwiR0OWbgqTVAhWFHJoKHU4CCjEQgQMIITAA\#search=\%22future\%20skills\%20oec $\mathrm{d} \% 22$ 
[11] All India Survey on Higher Education 2015-2016. (July 2017). Ministry of Human Resource Development, Government of India. Retrieved from http://aishe.nic.in/aishe/viewDocument.action;jsessionid=A4E24A7A3EFE2A844F3222A0F15C 8BF9?documentld=227

[12] NPTEL, A Project funded by MHRD, Govt. of India. (October 2017). Retrieved from http://www.nptel.ac.in/faq.php

[13] R. Ubell, How the Pioneers of the MOOC Got It. (16.1.2017). Retrieved from https://spectrum.ieee.org/tech-talk/at-work/education/how-the-pioneers-of-the-mooc-got-itwrong

[14] G. Christensen, A. Steinmetz, Br. Alcorn, A. Bennett, D. Woods \& E. Emanuel. The MOOC Phenomenon: Who Takes Massive Open Online Courses and Why? (November 6, 2013). Retrieved from https://ssrn.com/abstract=2350964 or http://dx.doi.org/10.2139/ssrn.2350964

[15] K. F. Hew \& W.S. Cheung, 'Students' and instructors' use of massive open online courses, (MOOCs): Motivations and challenges", Educational Research Review, vol. 12, pp. 45-58, 2014. Retrieved from http://www.sciencedirect.com/science/article/pii/S1747938X14000128

[16] J. Mackness \& F. Bell, "Rhizo14: A rhizomatic learning cMOOC in sunlight and in shade, "Open Praxis, 7(1), pp. 25-38, 2015. Retrieved from http://www.openpraxis.org/index.php/OpenPraxis/article/view/173/140

[17] O. Pilli \& W. Admiraal, "Students' Learning Outcomes in Massive Open Online Courses (MOOCs): Some Suggestions for Course Design," Yuksekogretim Dergisi 7, pp. 46-71, 2017. 10.2399/yod.17.001.

[18] T. Liyanagunawardena \& A. Adams, "The Impact and Reach of MOOCs: A Developing Countries' Perspective," in Elearning papers Special edition 2014, Transforming Education through Innovation and Technology, p.38-46, 2014. Retrieved from http://centaur.reading.ac.uk/38250/1/ELearning_2014_SpecialEditionImpactAndReachofMOOCs.pdf

[19] F. René, A. Kizilcec, J. Saltarelli, J. Reich \& G. L. Cohen. Closing global achievement gaps in MOOCs, Science 20, Vol. 355, Issue 6322, pp. 251-252, 20 Jan 2017. Retrieved from http://science.sciencemag.org/content/355/6322/251

[20] Sindhu Kashyap. How this Finnish startup is bringing personalised learning to the edutech. /09 July 2016). Retrieved from https://yourstory.com/2016/07/claned

[21] S. Hirsjärvi, P. Remes \& P. Sajavaara, Tutki JA kirjoita, Helsinki: Kustannusosakeyhtiö Tammi, 2009.

[22] K. Punia. Understanding the basics of e-learning industry. (19.11.2013). Retrieved from https://yourstory.com/2013/11/e-learning-industry/ 